\title{
TRITON: TOPSIDE IONOSPHERE AND NITROGEN ESCAPE
}

\author{
Y. L. Yung and J. R. Lyons
}

Division of Geological and Planetary Sciences, California Institute of Technology

The principal ion in the ionosphere of Triton is $\mathrm{N}^{+}$. Enersetic electrons of magnetospheric origin are the primary cource of ionization, with a smaller contribution due to photoionization. To explain the topside plasma scale beight, we postulate that $\mathrm{N}^{+}$ions escape from Triton. The loss rate is $3.4 \times 10^{7} \mathrm{~cm}^{-2} \mathrm{~s}^{-1}$ or $7.9 \times 10^{24}$ ions $0^{-1}$. Dissociative recombination of $\mathrm{N}_{2}^{+}$produces neuwal exothermic fragments that can escape from Triton. The rate is estimated to be $8.6 \times 10^{\circ} \mathrm{N} \mathrm{cm} \mathrm{cm}^{-2} \mathrm{~s}^{-1}$ or $2.0 \times 10^{24}$ atoms $\mathrm{s}^{-1}$. Implications for the magnetosphere of Neptune and Triton's evolution are discussed.

\section{Introduction}

The ionosphere of Triton discovered by Voyager 2 [Tyler a $d ., 1989$ ] is remarkable in many ways. First, the maxelectron concentration in ingress and egress is 2.3 $\times 10^{4}$ and $4.6 \times 10^{4} \mathrm{~cm}^{-3}$, respectively. These are very large numbers indeed, if we recall that Titan, with a simitar atmosphere $\left(\mathrm{N}_{2}\right)$ but much closer to the sun, has a peak electron density of less than $3 \times 10^{3} \mathrm{~cm}^{-3}$ [Lindal et. ., 1983]. The same experiment in Neptune reported en electron density that is less than $3 \times 10^{3} \mathrm{~cm}^{-3}$ (in an $\mathrm{B}_{2}$ atmosphere). The second puzzling feature of the ionophere is the topside plasma scale height $H_{p}=128 \pm 25$ ke. Now for either a molecular ion in photochemical equithbrium or an atomic ion in diffusive equilibrium (in the abence of large winds), we have $H_{p}=2 H_{r k}$ where $H_{r k}$ i the scale height of the corresponding neutral species [Atreya, 1986]. Therefore, $H_{n}=64 \mathrm{~km}$, a value very clowe to the neutral atmospheric scale height of $60 \mathrm{~km}$ (corresponding to $90 \mathrm{~K}$ ) deduced from the observations of the UVS experiments on the Voyager [Broadfoot et al., 1009 . Hence, it is tempting to identify the major ion as $\mathrm{N}_{2}^{+}$(Tyler et al., 1989]. We will show that this model will heve disastrous consequences. Third, the electron densitie drop off rapidly below the peak in a manner consisteat with the classical Chapman profile [Chamberlain and Hunten, 1987]. Firally, there is an asymmetry between ingrese (dawn) and egress (dusk) electron profiles by a fector of 2.

In this article we attempt to examine the simplest hypotheses needed to provide a satisfactory account of the copoide ionosphere of Triton. We rely heavily on the neutral modeling work of Strobel et al. [1990]. No attempt ba been made to provide a model that is self-consistent with the neutral species. Rather this is a preliminary attempt to propose and explore a new and bold hypothesis:

Copreight 1990 by the American Geophysical Union.

haex nuber 906L01465

14-8276/90/90GL-01465\$03.00 the topside ionosphere implies a massive escape rate of $\mathrm{N}^{+}$from Triton. The details are worthy of further investigation only if the major concepts prove correct. Unless otherwise stated, all results in this article are obtained by solving the coupled continuity equations for ions and electrons in a spherical atmosphere with transport by ambipolar diffusion [Banks and Kockarts, 1973] using the numerical code described in Allen et al. [1981]. Charge neutrality is rigorously preserved at each level of the atmosphere.

\section{Photochemical Models}

The model atmosphere adopted in this study is taken from Strobel et al. [1990] for exospheric temperature equal to $95 \mathrm{~K}$, as shown in Figure 1. The simplest model we can think of is one with energetic electrons impacting a pure $\mathrm{N}_{2}$ atmosphere as first proposed by Atreya [1989]. $\mathrm{N}_{2}$ is readily ionized,

$$
\mathrm{N}_{2}+e \rightarrow \mathrm{N}_{2}^{+}+2 e \text {, }
$$

followed by rapid recombination,

$$
\mathrm{N}_{2}^{+}+e \rightarrow \mathrm{N}+\mathrm{N}
$$

(See Table 1 for listing, numbering of reactions, and rate coefficients.) By trial and error we discovered that a monoenergetic electron beam with $E=20 \mathrm{keV}$ per electron and energy flux $F=0.4 \mathrm{erg} \mathrm{cm}^{-2} \mathrm{~s}^{-1}$ can simulate the essential features of the observed egress electron profite (for present purposes, further fine tuning is not necessary). But this model grossly violates other observations. The thermospheric temperature of $95 \mathrm{~K}$ suggests an energy influx of $1.6 \times 10^{-3} \mathrm{erg} \mathrm{cm} \mathrm{cm}^{-2} \mathrm{~s}^{-1}$ [Broadfoot et al., 1989|, which is considerably less than $0.4 \mathrm{erg}^{\mathrm{cm}} \mathrm{cm}^{-2} \mathrm{~s}^{-1}$ ! In addition, this large flux of energetic electrons will be accompanied by an induced $\mathrm{N}_{2} c_{4}^{\prime}$ state emission of about $200 \mathrm{R}$, which should be compared with the observed emission of 3-5 R. Hence, this model is entirely incompatible with the upper atınosphere energetics of Triton.

Can $\mathrm{N}^{+}$be the dominant ion in the jonosphere of Triton? $\mathrm{N}^{+}$is readily produced by electron impact,

$$
\mathrm{N}_{2}+e \rightarrow \mathrm{N}^{+}+\mathrm{N}+2 e
$$

and by photoionization,

$$
\mathrm{N}_{2}+h \nu \rightarrow \mathrm{N}^{+}+\mathrm{N}+\mathrm{e} .
$$

But this ion has the wrong scale height as explained in the Introduction. Now the relation $H_{p}=2 H_{n}$ as diocussed earlier holds in an equilibrium situation, but not in a dynamic situation. If the plasma in the atmosphere of Triton interacts with the Neptunian magnetosphere, this 
Table 1. List of reactions considered in our models. The units for rate coefficients are $\mathrm{s}^{-1}$ and $\mathrm{cm}^{3} \mathrm{~s}^{-1}$ for dissociative and two-body reactions, respectively. The values for photodissociation coefficients refer to diurnally averaged values at the top of the atmosphere.

\begin{tabular}{|c|c|c|c|c|c|}
\hline Rla & $\mathrm{N}_{2}+e$ & $\rightarrow$ & $\mathrm{N}_{2}^{+}+2 e$ & see text & (a) \\
\hline R1b & & $\rightarrow$ & $\mathrm{N}+\mathrm{N}^{+}+2 e$ & see text & (a) \\
\hline $\mathrm{R} 2 \mathrm{a}$ & $N_{2}+h \nu$ & $\rightarrow$ & $\mathrm{N}_{2}^{+}+e$ & $J_{2 n}=5.4 \times 10^{-10}$ & (b) \\
\hline $\mathrm{R} 2 \mathrm{~b}$ & & $\rightarrow$ & $\mathrm{N}+\mathrm{N}^{+}+e$ & $J_{2 b}=6.7 \times 10^{-11}$ & (b) \\
\hline R3 & $\mathrm{N}_{2}^{+}+\mathrm{N}$ & $\rightarrow$ & $\mathrm{N}_{2}+\mathrm{N}^{+}$ & $k_{2}=1.0 \times 10^{-11}$ & (c) \\
\hline $\mathrm{R} 4$ & $\mathrm{~N}_{2}^{+}+\mathrm{H}_{2}$ & $\rightarrow$ & $\mathrm{N}_{2} \mathrm{H}^{+}+\mathrm{H}$ & $k_{3}=1.7 \times 10^{-8}$ & (c) \\
\hline $\mathrm{R} .5$ & $\mathrm{~N}_{3}^{+}+\mathrm{H}$ & $\rightarrow$ & $\mathrm{N}_{2}+\mathrm{H}^{+}$ & $k_{4}=1.9 \times 10^{-10}$ & (c) \\
\hline R6 & $\mathrm{N}^{+}+\mathrm{H}_{2}$ & $\rightarrow$ & $\mathrm{NH}^{+}+\mathrm{H}$ & $k_{5}=7.0 \times 10^{-10}$ & (c) \\
\hline $\mathrm{R7}$ & $\mathrm{N}^{+}+\mathrm{H}$ & $\rightarrow$ & $\mathrm{N}+\mathrm{H}^{+}$ & $k_{5}=1.9 \times 10^{-10}$ & (d) \\
\hline R8 & $\mathrm{N}_{2}^{+}+e$ & $\rightarrow$ & $N+N$ & $\hbar_{7}=1.8 \times 10^{-7}\left(\frac{T}{300}\right)$ & (c) \\
\hline $\mathrm{R} 9$ & $\mathrm{~N}_{2} \mathrm{H}^{+}+e$ & $\rightarrow$ & $\mathrm{N}_{2}+\mathrm{H}$ & $k_{8}=5.0 \times 10^{-7}$ & (d) \\
\hline R10 & $\mathrm{NH}^{+}+e$ & $\rightarrow$ & $\mathrm{N}+\mathrm{H}$ & $k_{0}=2.0 \times 10^{-7}$ & (c) \\
\hline R11 & $\mathrm{N}^{+}+\mathrm{e}$ & & $\mathrm{N}+h \nu$ & $k_{10}=3.8 \times 10^{-12}\left(\frac{T}{300}\right)$ & (c) \\
\hline R12 & $\mathrm{H}^{+}+e$ & $\rightarrow$ & $\mathrm{II}+h \nu$ & $k_{11}=3.5 \times 10^{-12}\left(\frac{T}{300}\right.$ & (c) \\
\hline
\end{tabular}

(a) Cross-sections for electron impact are based on Ajello et al. [1989] and Krishnakumar and Srivastava [1990]. (b) Adopted in model B. Cross-sections taken from Kirby et al. [1979], Wu et al. [1984], and Morioka et al. [1984]. (c) Prasad and Huntress [1980]. (d) Estimated by analogy with similar reactions.

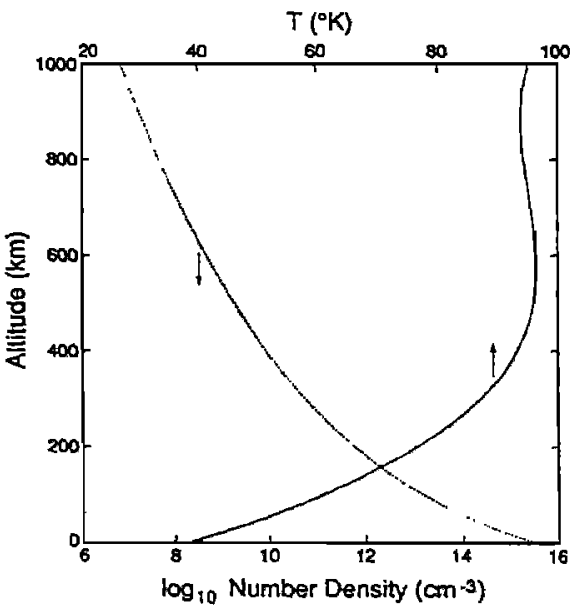

Figure 1. Model atmosphere of Triton adopted for ionospheric studies.

might lead to a loss of $\mathrm{N}^{+}$by escape from the exosphere. The loss of ionized particles at the upper boundary will lead to a steepening of the plasma gradient, resulting in a scale height $H_{p}<2 H_{n}$, as previously noted in the study of the ionosphere of Venus [Nagy et al., 1975].

To account for the loss of ions below the electron peak we invoke the presence of $\mathrm{H}_{2}$ in Triton's atmosphere [Strobel et al., 1990]. $\mathrm{N}^{+}$reacts with $\mathrm{H}_{2}$,

$$
\mathrm{N}^{+}+\mathrm{H}_{2} \rightarrow \mathrm{NH}^{+}+\mathrm{H},
$$

followed by,

$$
\mathrm{NH}^{+}+e \rightarrow \mathrm{H}+\mathrm{N},
$$

thus leading to a rapid loss of ionization below the iomspheric peak. $\mathrm{H}_{2}$ is also destroyed by $\mathrm{N}_{2}^{+}$in the following reactions,

$$
\begin{aligned}
\mathrm{N}_{2}^{+}+\mathrm{H}_{2} & \rightarrow \mathrm{N}_{3} \mathrm{H}^{+}+\mathrm{H} \\
\mathrm{N}_{2} \mathrm{H}^{+}+e & \rightarrow \mathrm{N}_{2}+\mathrm{H},
\end{aligned}
$$

resulting in a net conversion of $\mathrm{H}_{2}$ to $2 \mathrm{H}$. Ultimntely, $\mathrm{H}^{+}$'s are also formed. We assume that $\mathrm{H}^{+}$will diffese to the lower atmosphere and charge transfer to $\mathrm{CH}_{4}$ or diffuse to the exosphere and escape from Triton. For sim plicity, we do not include $\mathrm{H}^{+}$in the model. As will be discussed later, we do not intend to conduct a thorongh investigation of the bottomside ionosphere in this article.

Therefore, by introducing additional loss procenes may obtain an ionospheric profile that can simulate the essential features of the observed profile. However, this demands a higher ionization rate to compensate for the greater losses. Model runs (not shown) indicate that photoionization alone is far from being adequate (see latw discussion). Electron impact is invoked as an additioani source of ionization. By trial and error we arrived a a model shown in Figure 2. At the upper boundary, excapt fluxes are given by $n v_{\text {eec }}$ where $n$ denotes the concentrtion of a species and $v_{\text {eac }}$ is its escape velocity. At the lower boundary, the mixing ratio of $\mathrm{H}_{2}, f_{\mathrm{H}_{2}}$, is fixed, and those of $\mathrm{N}^{+}$and $\mathrm{N}_{2}^{+}$are set to zero. The model prow ine a fairly good fit to the oberved topside ionosphere, cept perhap near the upper boundary, where the relatiwe uncertanties in the observed electron densities are hrom The major ion is $\mathrm{N}^{+}, \mathrm{N}_{2}^{+}$is less abundent due to 


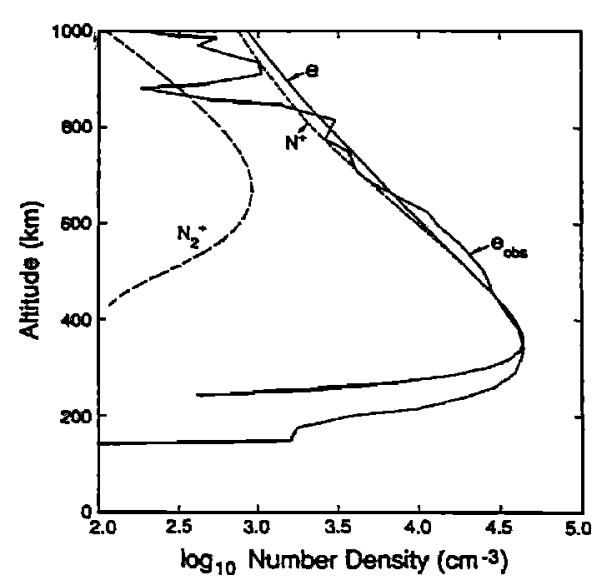

Fyare 2. Comparison of model ionospheric profile (e) with Voyager egress observations ( $e_{\text {ohs }}$ ). The uncertainty in $e_{\mathrm{ob}}$ is $\pm 2.3 \times 10^{3} \mathrm{~cm}^{-3}$ [Tyler et al., 1989]. Conditions of this model were: $f_{\mathrm{H}_{3}}=1 \times 10^{-6}$ at the lower boundary $(189 \mathrm{~km})$ and $v_{\mathrm{esc}}=7 \times 10^{3}$, $1.5 \times 10^{4}, 0 \mathrm{~cm} \mathrm{~s}^{-1}$ for $\mathrm{H}_{2}, \mathrm{~N}^{+}$and $\mathrm{N}_{2}^{+}$respectively at the upper boundary $(974 \mathrm{~km})$.

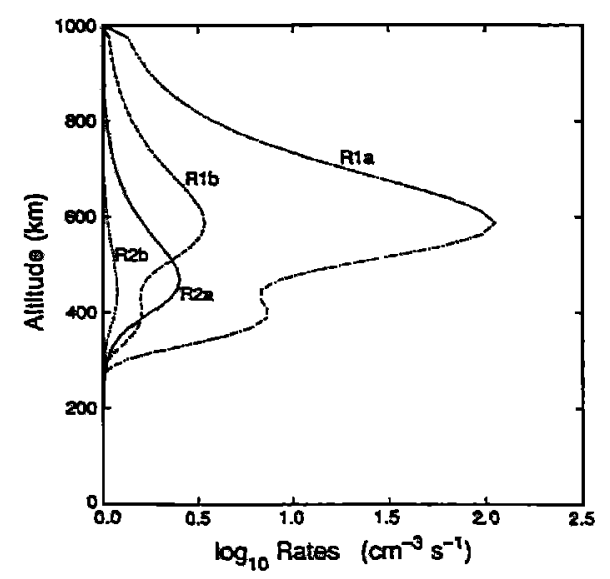

Figure 3. Ionization rates by electron impact and sunlight in the inodel. R1a: $\mathrm{N}_{2}+e \rightarrow \mathrm{N}_{2}^{+}+2 e$; R1b: $\mathrm{N}_{2}+$ $e \rightarrow \mathrm{N}+\mathrm{N}^{+}+2 e ; \mathrm{R} 2 \mathrm{a}: \mathrm{N}_{2}+h \nu \rightarrow \mathrm{N}_{2}^{+}+e ; \mathrm{R} 2 \mathrm{~b}:$ $\mathrm{N}_{2}+h \nu \rightarrow \mathrm{N}+\mathrm{N}^{+}+e$. The integrated energy fluxes are $2 \times 10^{-9}, 6.7 \times 10^{-3}$ and $2.4 \times 10^{-3} \mathrm{erg} \mathrm{cm}^{-2} \mathrm{~s}^{-1}$ for EUV solar flux (R1), $0.5 \mathrm{keV}$ electrons and 20 keV electrons (R2), respectively.

cient dissociative recombination. The concentrations of the other ions $\mathrm{N}_{2} \mathrm{H}^{+}$and $\mathrm{NH}^{+}$are much less than those $0 \mathrm{~N}^{+}$and $\mathrm{N}_{2}^{+}$, and are therefore not shown.

The contributions to ion production rates in the model are presented in Figure 3. The principal source of ionization is electron impact by soft electrons (0.5 $\mathrm{keV}), \mathrm{R} 1 \mathrm{a}$ and RIb. The aecondary peaks in RIa and RIb at lower hitude are due to hard electrons (20 keV). Photoionization (diurnally averaged and appropriate for egress conditions, denoted by $\mathrm{R2a}$ and R2b in Figure 3, provides als minor source of ionization. We note that a large Aux of solt electrons is required to explain the bulge near $00 \mathrm{~km}$ in the observed electron profile. If an alternative aplanation such es plasma compression were found, then this large flux would become unnecessary (see later discussion). The hard electrons are needed to reproduce the observed electron peak.

To test the sensitivity of the model to input parameters and boundary conditions we conducted a number of sensitivity runs in which one change was made at a time. The results are presented in Figure 4. In cases $A$ and $B$, the soft $(0.5 \mathrm{keV})$ and hard $(20 \mathrm{keV})$ electrons were, respectively, "switched off." In case $C$, the escape velocity for $\mathrm{N}^{+}$at the upper boundary $v_{\text {exx }}\left(\mathrm{N}^{+}\right)$was increased by a factor of 3 to $4.5 \times 10^{4} \mathrm{~cm} \mathrm{~s}^{-1}$, resulting in an electron profile with a smaller scale height than that in the standard case. In case $\mathrm{D}, v_{\text {ear }}\left(\mathrm{N}^{+}\right)$was reduced by the same factor to $0.5 \times 10^{4} \mathrm{~cm} \mathrm{~s}^{-1}$, resulting in an electron profile with a much larger scale height relative to that in case C. Thus, the magnitude of $v_{\text {ene }}$ has a major impact on the slope of electron densities.

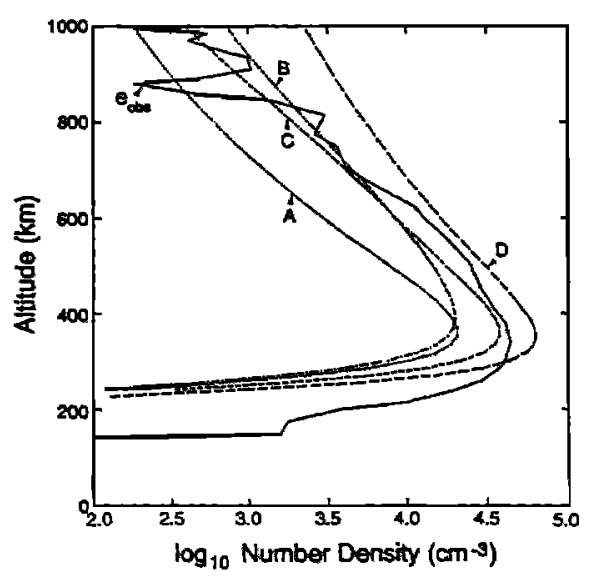

Figure 4. Sensitivity study of model electron profile to variations in input parameters and boundary conditions in the standard model (see Table 2). enha observed; A: without $0.5 \mathrm{keV}$ electrons; $B$ : without 20 keV electrons; C: $v_{\operatorname{mr}}\left(\mathrm{N}^{+}\right)=4.5 \times 10^{4} \mathrm{~cm} \mathrm{~s}^{-1} ; \mathrm{D}$ : $v_{\text {enc }}\left(\mathrm{N}^{+}\right)=0.5 \times 10^{4} \mathrm{~cm} \mathrm{~s}^{-1}$.

Given the crudeness of the model described in this work, we can only point out the inadequacies, which will be remedied in a subsequent publication: diurnal variation, lower ionosphere, energy source and uniqueness.

\section{Concluding Remarks}

The interaction between Triton and the Neptunian magnetosphere is primarily responsible for generating and maintaining the ionosphere of Triton. Impact by electrons is the principal source of ionization. $\mathrm{N}^{+}$is the major ion. Its loss from the atmosphere by scape is surprising but the process may be characteristic of planetary bodies without a magnetic field such as Mars and Venus. The rate of loss of nitrogen (as $\mathrm{N}^{+}$or $\mathrm{N}$ ) from Triton is $4.3 \times 10^{7} \mathrm{~cm}^{-2} \mathrm{~s}^{-1}$ (normalized to the surface of the satellite) or $1 \times 10^{25} \mathrm{~s}^{-1}$. The heavy ion in Neptune's magnetosphere observed by the Voyager Plasma Science experiment (Belcher et al., 1989) has been tentatively identified as $\mathrm{N}^{+}$. The lifetime of magnetospheric ions may be very short ( $\sim$ a few daya), and indepen- 
dent of mass [Selesnick, 1990]. The required nitrogen flux to sustain the $\mathrm{N}^{+}$concentrations in the magnetosphere is of the order of $10^{25} \mathrm{~s}^{-1}$ [Richardson and McNutt, 1990; Richardson et al., 1990], consistent with that deduced from our model. At this rate, the total integrated loss of material from Triton is $3.1 \times 10^{24} \mathrm{~N}_{3}$ molecules $\mathrm{cm}^{-2}$ or 11 mbars over the age of the solar system. The escape flux of nitrogen deduced from our model is comparable to that of hydrogen computed by Strobel et al. [1990] and suggest that the chemistry of $\mathrm{N}_{3}$ and $\mathrm{H}_{2}$ may be strongly coupled. The incident energy flux in the model (if globally uniform) is somewhat higher than that deduced by the Voyager UVS experiment [Broadfoot et al., 1989].

In this article we have examined the simplest possible ionospheric models. A self-consistent diumally varying model between the ion chemistry and that of $\mathrm{CH}_{4}$ (which supplies $\mathrm{H}_{2}$ to the upper atmosphere) remains to be developed, and is expected to remove some of the difficulties associated with the current simple model.

Acknowledgements. We thank M. Summers, D. Strobel, J. Richardson, R. Selesnick, and S. Srivastava for communicating to us their results prior to publication, and $M$. Allen and S. Trajmar for valuable discussions. This work is supported in part by NASA grant NAGW 1509 to the California Institute of Technology, and by the Jet Propulsion Laboratory, California Institute of Technology under contract with NASA. Contribution number 4860 from the Division of Geological and Planetary Sciences, California Institute of Technology, Pasadena, California 91125.

\section{References}

Ajello, J. M., G. K. James, B. O. Franklin, and D. E. Shemansky, Medium-resolution studies of extreine ultraviolet emission from $\mathrm{N}_{2}$ by electron impact: Vibrational perturbations and cross sections of the $c_{4}^{\prime} \Sigma_{u}^{+}$and $b^{\prime} \Sigma_{u}^{+}$ states, Phys. Rev., 40, 3524-3556, 1989.

Allen, M., Y. L. Yung, and J. W. Waters, Vertical transport and photochemistry in terrestrial mesosphere and lower thermosphere (50-120 km), J. Geophys. Res., 86, 3617-3627, 1981.

Atreya, S. K., Atmospheres and Ionospheres of the Outer Planets and their Satellites, 224 pp., Springer-Verlag, Heidelberg 1986.

Atreya, S. K., Neptune's ionosphere, EOS, 70, 381, 1989.

Banks, P. M., and Kockarts, G., Aeronamy, Part $A$ and $B$, Academic Press, New York, 1973.

Belcher, J. W. et al., Plasma observations near Neptune: Initial results from Voyager 2, Science, 246, 1478-1483, 1989.

Bauer, S., and R. E. Hartle, Venus ionosphere: An interpretation of Mariner 10 observations, Geophys. Res. Lett., 1, 7-9, 1974.

Broadfoot, A. L., et al., Ultraviolet spectrometer observations of Neptune and Triton, Seience, 246, 1459-1466, 1989.

Chamberlain, J. W., and D. M. Hunten, Theory of Planetary Atmospheres, end ed, Academic Press, San Diego,
CA, 1987.

Kirby, K., E. R. Constantinides, S. Babeu, M. Oppea heiraer, and G. A. Victor, Photoionization and photoabsorption cross sections of $\mathrm{He}, \mathrm{O}, \mathrm{N}_{2}$ and $\mathrm{O}_{2}$ for aeronomic calculations, Atomic Data Nucl. Data $\mathrm{Ta}$ bles, 23, 63-81, 1979.

Krishnakumar, E. and S. K. Srivastava, Cross-sections for the production of $\mathrm{N}_{2}^{+}, \mathrm{N}^{+}+\mathrm{N}_{2}{ }^{2+}$ and $\mathrm{N}^{2+}$ by electron impact on $\mathrm{N}_{2}, J$. Phys. B: At. and Mol. Opt. Phys, in press, 1990.

Lindal, G. F., G. E. Wood, H. B. Hotz, D. N. Sweetgana, V. R. Eshleman, and G. L. Tyler, The atmosphere of Titan: An analysis of Voyager 1 radio occultation measurements, Icarus, 53, 348-363, 1983.

Morioke, Y., S. Aoyama, Y. Kageyama, T. Hayaishi, I. I Suzuki, G. Isoyama, S. Asaoka, E. Ishiguro, and M. Nakamura, Dissociative photoionization of $\mathrm{N}_{2}$ froe threshold to $29 \mathrm{eV}, J$. Phys. B At. Mol. Phys., 1T, 2795-2802, 1984.

Nagy, A. F., S. C. Liu, T. M. Donahue, S. K. Atrepe and P. M. Banks, $A$ model of the Venus ionosphere, Geophys. Res. Lett., 2, 83-86, 1975.

Prasad, S. S., and W. T. Huntress, Jr., A model for gas phase chemistry in interstellar clouds: I. The bo sic model, library of chemical reactions, and chemistsy among $\mathrm{C}, \mathrm{N}$, and $\mathrm{O}$ compounds, Astrophys. J. Suph, 43, 1-35, 1980.

Richardson, J. D., A. Eviatar, and M. L. Delishy, The Triton torus revisited, Geophys. Res. Lett., this inoe, 1990.

Richardson, J. D., and R. L. McNutt, Jr., Low-enersy plasma in Neptune's magnetosphere, Geophys. Res. Lett., this issue, 1990.

Selesnick, R. S., Plasma convection in Neptune's mage tosphere, Geophys. Res. Lett., this issue, 1990.

Strobel, D. F., M. E. Summers, F. Herbert, and B. Sandel, The photochemistry of methane in the two sphere of Triton, Geophys. Res. Lett., this issue, 1920.

Torr, M. R., and D. G. Torr, Ionization frequescio for solar cycle 21: Revised, J. Geophys. Res., 90, 6675$6678,1985$.

Tyler, G. L. et al., Voyager radio science obeervation of Neptune and Triton, Science, 246, 1466-1473, 1909.

Wu, C. Y. R., L. C. Lee, and D. L. Judge, Fhore cence from photofragments as an aid in identifying now molecular states: The $\mathrm{N}_{2}$ case, J. Chem. Phys., 80. 4682-4685, 1984.

Y. L. Yung, Division of Geological and Planetary Sci ences, California Institute of Technology, Pasadena, Cat ifornia 91125.

J. R. Lyons, Telecommunications Systems Section, Jet Propulsion Laboratory, 4800 Oak Grove Drive, Pasedent. California 91109.

(Received: April 20, 1990;

revised: June 12, 1990;

accepted: June 25,1990 .) 